Funding

\section{Differing priorities for medical research funding}

M A Patton

Commentary on the paper by Hawkins and Law (see page 1107)

A dvocacy can be a powerful force for change and those who work with children are the best advocates for the next generation. Drs Hawkins and Law have surveyed the pattern of research funding available for child and family health and have looked to see how this correlates with the government priorities for children set in the National Service Framework for Children and other government policy documents. ${ }^{1}$ Using a web based search of funding organisations they have found that the overall proportion of funding devoted to children is approximately 3\%, and even lower proportions of funding are devoted to government priorities such as health inequality and adolescent services. By comparison the National Institutes for Health in the United States devotes about 11-12\% of its budget to paediatrics. ${ }^{2}$

Children are not small adults. The research on adults will not necessarily be applicable to children. For example, they will have a different range of diseases and children have different responses to drugs. ${ }^{3}$ Some of this research is difficult to fund. There may be a reluctance to fund pharmaceutical trials on children as the commercial market for children's medication is small and there may be ethical difficulties in recruiting control subjects for such studies. However in some cases it is the paediatric research that provides solutions for other age groups. With cochlear implants the research into congenital sensorineural deafness in childhood has pioneered the way for cochlear implantation to be considered in other age groups. ${ }^{4}$

In funding research there are many conflicting strategies and no one perfect answer. There has been a conflict between directing research from the "top down" and responding to research requests from those already in the field looking for "bottom up" funding. Top down money devoted to research will not always solve the problems that have been decided in government strategy. Thus research into health inequalities can provide the necessary information about the problem, but ultimately the solution is an economic or political one. Such discussions also draw attention to the conflict between applied and basic research. Basic research does not bring instant answers but ultimately has transformed our approach to medicine. The authors of the paper only included basic research if it was explicitly related to child or maternal health. How would they have rated the $x$ ray crystallography Watson and Crick? It certainly did not set out to solve inherited disease in childhood but the ultimate spin off over many decades may be one of the most profound developments in paediatrics. It also shows how unpredictable scientific research can be. Those who want to plan medical research centrally might be surprised to read Roberts' monograph on serendipity ${ }^{5}$ and to see how, as Pasteur put it, "chance favours the prepared mind".

There are many sources of funding for medical research in the UK and we are fortunate to have a substantial proportion of charitable funding. It would be appropriate for the Department of Health to allocate its own research and development funding along the priorities laid down by the National Service Framework. However the charities, private sources of funding, and indeed other government bodies such as the research councils have their own independent governance and will correctly have their own priorities. The research councils and the major research charities have supported basic research and built a very strong bioscience base in the universities in the United Kingdom. Other charities supporting a specific disease have supported clinical research. This is particularly important where the current Research Assessment Exercise that led to the discovery of DNA by in our universities has often favoured basic research at the expense of clinical studies. $^{6}$

In the accompanying paper by Hawkins and Law, ${ }^{1}$ almost half of the identified funding for child and family health research comes from the charitable sector. This may still be an underestimate as the authors were unable to locate the funding allocation from smaller charities by their web based search methodology. This shows the immense importance of charitable funding in the UK and this puts us in a favourable position compared with most European countries. Many charities will support a specific childhood disorder such as cystic fibrosis or spina bifida and will therefore devote almost 100\% of their funding to child and family health research. This focus has helped those charities in their fundraising and reflects the public support for research into childhood disability.

We need a diversity of funding strategies so that more research ideas will fall on fertile ground and new ideas can be developed. It is wrong to assume that all research funding bodies should follow the governmental policy strategy. However, these authors have shown the level of government funding allocated for child and family health does not reflect the importance of children in our future. More clinical evidence is also required to ensure that the allocation of government healthcare funding for children provides the best possible value and outcome for children.

Arch Dis Child 2005;90:1101

doi: 10.1136/adc.2005.075838

Correspondence to: Prof. M A Patton, Department of Medical Genetics, St George's Hospital Medical School, Cranmer Terrace, London SW17 ORE, UK; mpatton@sghms.ac.uk

Competing interests: the author is Medical Director of Birth Defects Foundation UK

\section{REFERENCES}

1 Hawkins SS, Law C. Patterns of research activity related to government policy: a UK web based survey. Arch Dis Child 2005;90:1107-11.

2 Gitterman DP, Greenwood RS, Kocis KC, et al. Did a rising tide lift all boats? The NIH budget and pediatric research portfolio. Health Aff (Millwood) 2004;23:113-24.

3 Stephenson T. How children's responses to drugs differ from adults. Br J Clin Pharmacol 2005;59:670-3.

4 Sach TH, Whynes DK, Parker $\mathrm{P}$, et al. Innovation and funding specialist services. Cochlear implantation. J Health Organ Manag 2004; 18:53-63.

5 Roberts RM. Serendipity: accidental discoveries in science. John Wiley \& Sons, 1989

6 Banatvala J, Bell P, Symonds M. The Research Assessment Exercise is bad for UK medicine. Lancet 2004;365:458-60. 
Emergency medicine

\section{Paediatric cardiac resuscitation: can we do better?}

\section{R C Tasker}

\section{Commentary on the paper by Tibballs et al (see page 1148)}

O ver a relatively short period in the evolution of hospital practice, some 45 years, cardiopulmonary resuscitation (CPR) has moved from its historical position as a new experimental technique in adults ${ }^{1}$ to its current, clinically pervasive status where we expect all hospital based paediatricians to be proficient and competent in life saving procedures. $^{23}$ In this issue, Tibballs et al from the Royal Children's Hospital (RCH), Melbourne, present a new development in this story. ${ }^{4}$ That is, the introduction of a specialist paediatric emergency team charged with improving in-patient safety and providing urgent assistance whenever it is requested-not just for cardiac arrest. On initial reading you may wonder, "isn't that what we did when we were residents on-call?". In the following commentary we will explore the arguments and observations that indicate the importance of this Australian development.

Unexpected cardiac arrest is a rare event in paediatric in-patients. Tibballs et al observed 20 instances in almost 105000 admissions over a period of 41 months - that is, $\sim 1$ per 5000 admissions. If we translate this figure to a typical UK district general hospital paediatric unit (and set aside issues such as potential differences in patient acuity and case mix) then we should have no more than one or two unexpected in-patient cardiac arrests a year. This estimate does raise an important question that will warrant local audit and investigation: if we see much more than 1 cardiac arrest per 5000 admissions, then we should be asking ourselves why. ${ }^{5}$ The answer could lie in a change in pattern of disease or practice, unappreciated severity of illness, or unusual circumstances-sometimes even criminal. In regard to the issue of whether we can do better with CPR there is a more pertinent question though: is this activity frequent enough to maintain skills in all attendant clinical staff working in a particular unit? One response to this question may be to think that since there are educational systems in place to ensure all clinicians have annual training in resuscitation skills (for example, Basic Life Support, Advanced Paediatric Life Support, or Pediatric Advanced Life Support (PALS) courses), then it doesn't matter that CPR is needed rarely. Paediatricians are well prepared on surrogates of this activity with life-like clinical scenarios and manikins. There are two indications that this argument may not be correct. First, there is the influence of "self-efficacy" on performing CPR. ${ }^{6}$ This is not the same as selfconfidence which is a relatively stable personality trait that may or may not be founded in reality. Self-efficacy varies; it may mean that despite appropriate knowledge and training, in an emergency, resuscitation techniques and practical procedures may fail to be skilfully applied unless the operator also has an adequately strong belief in their capability. For example, Simon and Sullivan" examined "confidence in performance" of paediatric emergency procedures in 117 suitably qualified physicians. Over one quarter of them were uncomfortable with performing certain essential life-saving procedures (for example, tracheotomy tube change) that the American Academy of Pediatrics recommended competence in for paediatric emergency specialists.

The second indication that there could be a problem with our current system of maintaining "expertise" was identified earlier this year by Abella and colleagues. ${ }^{8}$ These researchers observed performance of resuscitation teams doing CPR in 67 adult, in-hospital, cardiac arrests by using a special defibrillator with monitoring features. A number of parameters of real-time CPR quality (for example, chest compression rate and depth, ventilation rate, and the fraction of arrest time without chest compressions) were followed; the authors came to the conclusion that CPR delivered at the bedside "was inconsistent and did not meet published guideline recommendations, even when performed by well-trained hospital staff". This is not an unexpected conclusion, particularly when we consider the complexity of CPR. ${ }^{9}$ There is also no reason to suppose that a study of paediatric CPR teams would be any different. For example, in a resuscitation scenario requiring emergency defibrillation, White et al found that $90 \%$ of PALS trained, paediatric residents in a university based training programme discharged the defibrillator only after a dangerously long pause-on average after 149 seconds. $^{10}$ Therefore if education, practice, and clinical opportunity cannot make us perform adequate CPR in the real world, then is there a better strategy?

Yes there is-we may be able to prevent cardiac arrests from occurring. The international ACADEMIA (a comparison of Antecedents to Cardiac Arrests, Deaths and EMergency Intensive care Admissions) study of 638 in-hospital emergency events, in 627 adults, found that in $60 \%$ of these instances there were significant preceding derangements in vital signs. ${ }^{11}$ These so-called "antecedents" were categorised as follows: threatened airway obstruction, abnormality in breathing rate and pulse rate (too fast or too slow), low blood pressure, and altered mental state (fall in Glasgow Coma Scale (GCS) score by two or more points). Almost 500 antecedents were present in the period from 15 minutes to 24 hours before the emergency event-the most common being hypotension and fall in GCS. This finding should not surprise us-after all there is a reason why we monitor vital signs in hospital practice. ${ }^{12}$ Over a century ago Carl Wunderlich (1815-77) and Etienne-Jules Marey (1830-1904) each developed sequential, clinical recording of patient temperature, pulse rate, and respiration. Marey even considered that the best expression of change in medical state was to have "....all the phenomena of life-movements which are so light and fleeting, changes of form so slow or rapid, that they escape the senses-an objective form must be given to them..." The work from the $\mathrm{RCH}$ follows in this tradition, and extends the findings of the ACADEMIA study. The assumption being: since in-patient cardiac arrests are preceded by deterioration in vital signs, then certain criteria should be used for gaining "urgent assistance". The criteria used by Tibballs et al included paediatric thresholds for antecedents identified in the ACADEMIA study - threatened airway obstruction, tachypnoea, tachycardia or bradycardia, hypotension, and altered mental stateas well as low pulse oximetry values and whether the attendant was "worried" about the child's state. Before using this system of emergency in-patient care Tibballs et al found that there were 20 cardiac arrests in almost 105000 admissions, and 13 of these 20 children died. 


\section{PERSPECTIVES}

In the year after introduction of the "urgent assistance" system, there were four cardiac arrests (with two deaths) in almost 36000 admissions (that is, $\sim 0.6$ per 5000 admissions), and 181 calls requesting the emergency team (that is, 25 calls per 5000 admissions). The difference in rate of cardiac arrest was not statistically significant in this before-and-after study, but the direction of trend in a large number of patients is encouraging. Early identification of atrisk patients may therefore be the answer to improved in-patient safety and outcome. That is, doing better by trying to prevent in-patient cardiac arrest from occurring.

The implementation of the new system of "urgent assistance" in the RCH required what the authors called an "organisational change". The last question we will consider in this commentary then is whether the organisational model Tibballs et al describe is applicable and practicable in places other than a children's hospital with $\sim 36000$ inpatients a year; and if not, are there improvements that we can make in our own centres? Tibballs et al give an account of two changes they brought about. First, they changed the prevailing medical and nursing culture in their centre and empowered all staff to call for urgent assistance when required. Over a period of three months they instituted a hospital-wide educational campaign-Sick Child Workshops-on the clinical features of serious illness. We can all learn from this institutional commitment to patient safety and education. Our own centres and personnel would clearly benefit from such investment. Second, they built a multidisciplinary, in-patient "urgent assistance" team-comprising paediatric intensive care unit (PICU) consultant or registrar, PICU nurse, emergency department (ED) senior doctor, and medical registrar-to support bedside nurses and doctors. Few centres can provide an emergency team of similar composition to the RCH team. However, there may be an alternative solution. In their first year, the $\mathrm{RCH}$ team dealt with $\sim 1$ cardiac arrest and $\sim 50$ emergency calls per 10000 admissions. In a UK paediatric unit, these figures could be translated into in-patient cardiac arrests being a rare event at the cost of, on average, one "urgent assistance" call per week. But there does need to be senior expertise, technical ability, and support readily available to provide the level of assistance required: a leader and team that is in some way equivalent to the RCH combined PICU, ED, and medical "urgent assistance" team, and not solely reliant on paediatric residents or specialist registrars (see above). A possible solution in the UK, identified by the Royal College of Paediatrics and Child Health, is to have acute consultants being resident on-call. ${ }^{13}$ Robert ScottJupp recently described his experience of sleeping in and what it meant for him. ${ }^{14}$ The bottom-line is that "sicker children get a speedy, mature assessment and a decision on transfer for intensive care where appropriate". As far as he is concerned, his patients are safer.

Providing better paediatric in-patient resuscitation is an issue filled with complexity. At one level we can be better educated and practiced. However, in the real world of emergency care, Abella et al have shown that we need to improve our delivery of CPR. ${ }^{8}$ We could try and improve our technique and team performance, but if we really want to improve the effectiveness of inpatient CPR, perhaps it is time to reexplore mechanical aids that can undertake adequate and consistent repetitive, resuscitative actions. ${ }^{19}$ At another level-preventing the need for CPRthe preliminary report from the $\mathrm{RCH}$ describes an important development in hospital paediatrics. Tibballs et al suggest that our system for urgent assistance of in-patients also needs to change. The exact solution will depend on our practice and place of work, and our human resources. Whichever healthcare model we choose it will, by necessity, require more involvement of senior clinicians-perhaps a new breed or generation of them..$^{13-15}$
Arch Dis Child 2005;90:1 102-1 103. doi: 10.1136/adc.2005.076406

Correspondence to: Dr R C Tasker, University of Cambridge School of Clinical Medicine,

Department of Paediatrics, Box 116

Addenbrooke's Hospital, Hills Road,

Cambridge CB2 2QQ, UK; rcł31@cam.ac.uk

Competing interests: none

\section{REFERENCES}

1 Eisenberg MS. Life in the balance: emergency medicine and the quest to reverse sudden death. Oxford: Oxford University Press, 1997.

2 Buss PW, McCabe M, Evans RJ, et al. A survey of basic resuscitation knowledge among resident paediatricians. Arch Dis Child 1993;68:75-8

3 Brady RM, Raftos J. Emergency management skills of South Australian paediatric trainees. J Paediatr Child Health 1997:33:113-16.

4 Tibballs J, Kinney S, Duke T, et al. Reduction of paediatric in-patient cardiac arrest and death with a medical emergency team: preliminary results. Arch Dis Child 2005;90:1148-52.

5 Department of Health. An organisation with a memory. London: Department of Health, 2000.

6 Maibach EW, Schieber RA, Carroll MF. Selfefficacy in pediatric resuscitation: implications for education and performance. Pediatrics 1996;97:94-9

7 Simon HK, Sullivan F. Confidence in performance of pediatric emergency medicine procedures by community emergency practitioners. Pediatr Emerg Care 1996;12:336-9.

8 Abella BS, Alvarado JP, Myklebust $\mathrm{H}$, et al. Quality of cardiopulmonary resuscitation during in-hospital cardiac arrest. JAMA 2005;293:305-10.

9 Sanders AB, Ewy GA. Cardiopulmonary resuscitation in the real world: when will the guidelines get the message? JAMA 2005;293:363-5.

10 White JR, Shugerman R, Brownlee C, et al Performance of advanced resuscitation skills by pediatric housestaff. Arch Pediatr Adolesc Med 1998; 152:1232-5.

11 Kause J, Smith G, Prytherch D, et al. A comparison of antecedents to cardiac arrests, deaths and emergency intensive care admissions in Australia and New Zealand, and the United Kingdom - the ACADEMIA study. Resuscitation 2004;62:275-82.

12 Porter R. The greatest benefit to mankind: a medical history of humanity from antiquity to the present. London: Harper Collins, 1997:345-6.

13 Royal College of Paediatrics and Child Health. A Charter for Paediatricians. www.rcpch.ac.uk/ Charter for Paediatricians. www.rcpch.ac.uk/
publications/recent_publications/charter.pdf (p 26).

14 Scott-Jupp R. Consultants sleeping in. BMJ Careers 9 April 2005:145-6.

15 Bellet PS, Wachter RM. The hospitalist movement and its implications for the care of hospitalised children. Pediatrics

1999;103:473-7. 
Tuberculosis

\section{Diagnosing tuberculosis}

\section{U Heininger}

\section{Commentary on the paper by Swingler et al (see page 1153)}

A Ithough pulmonary tuberculosis is now reasonably well controlled in most industrialised countries, it still is a major and even increasing medical problem from a global perspective. The World Health Organisation estimated there were 8.8 million new cases worldwide in 2002, with case numbers currently growing by $2.4 \%$ per year. ${ }^{1}$ Many problems surround the fight against tuberculosis, including the emergence of multi-drug resistant Mycobacterium tuberculosis, compliance with treatment, and identification of new cases in order to avoid further spread of the disease. In children, who contract rather than transmit $M$ tuberculosis, early diagnosis followed by appropriate treatment is important to reduce morbidity and mortality. ${ }^{2}$ However, the frequently non-specific symptoms of disease, interference of BCG immunisation with tuberculin skin testing, uncertainties with the interpretation of $x$ ray findings, and the rare isolation of organisms from bronchial secretions are all factors that contribute to the difficulty in diagnosing pulmonary tuberculosis in children.

In this respect, the work published by Swingler and collaborators in this issue of the Archives of Disease in Childhood is to be applauded. ${ }^{3}$ This was a prospective cross sectional study from South Africa, an area with a yearly incidence of tuberculosis reaching almost 500/ 100000 . The diagnostic accuracy of conventional chest $x$ rays (CXR) in detecting enlarged lymph nodes was assessed in children with clinically suspected pulmonary tuberculosis (see article in this issue for definition). In contrast to previous studies on this topic, not only was inter-observer agreement assessed, where agreement between observers does not guarantee that the diagnosis is correct, but spiral chest computerised tomography (CT) scans with contrast injection were used as the reference standard, where any lymph node measuring at least $1 \mathrm{~cm}$ in any dimension was considered a positive finding. The reference was established by a paediatric radiologist blinded to CXR findings. The expert panel for chest $x$ rays consisted of three paediatricians and three primary care clinicians with a special interest in tuberculosis who were blinded to the CT results. Physicians knew about the suspected tuberculosis, but it is not stated clearly whether further medical details of individual patients were known to the reviewers or whether members of the panel were also in charge of clinical care for these patients. Furthermore, we do not know if indirect evidence of tuberculous lymphadenitis, such as obstructive hyperaeration or atelectasis, was searched for on the films. These limitations need to be kept in mind. Statistical methods were sound and 100 consecutive children were enrolled.

Overall, the accuracy of CXR interpretation was disappointing.

First, sensitivity and specificity were $67 \%$ and $59 \%$, respectively. In other words, a third of enlarged lymph nodes, as determined by the reference method, were not detected on CXR and almost half of supposedly enlarged lymph nodes on CXR were not confirmed by CT. While the lack of sensitivity may delay or even prevent diagnosis, the lack of specificity could lead to unnecessary further diagnostic tests and/or unjustified treatment. But is this really the case? Doubtless, spiral CT is not available in most health care settings and radiographic imaging in cases of suspected tuberculosis rests on conventional CXR in most centres. However, no data are available which would confirm that tuberculosis is overlooked on initial $x$ rays to such an extent nor do we know the magnitude of erroneous treatments for presumed pulmonary tuberculosis which in fact is not pre sent in the patient. As a major limitation of this study, no data on the clinical course of the patients, any further imaging studies performed later in the course of suspected tuberculosis, or microbiological confirmation of tuberculosis is provided. This makes final interpretation of the accuracy of the reference standard impossible.

Second, in contrast to current textbook recommendations, assessment of both antero-posterior and lateral CXR did not improve sensitivity significantly. ${ }^{4}$ This has major implications because, if a second view does not improve detection of enlarged lymph nodes, radiation exposure could be reduced and resources thus be saved.

The validity of the reference standard, that is the CT scans, is most critical. A companion paper from members of the South African group spreads doubt about its reliability. ${ }^{5}$ Using the same cohort of 100 children, the paediatric radiologist's lymph node assessments of the CT scans were controlled by three other radiologists independently. Unfortunately, the $\kappa$ statistics, as a measure of agreement beyond chance, were only in the range of 0.6 , which is generally considered to be only moderate. $^{6}$

However, where CT is available, this could prove to be a useful tool in cases of children with suspected pulmonary tuberculosis in the future, as is suggested by the findings of this study. Whether CT should be performed instead of or in addition to conventional CXR will remain a matter of debate until results from further studies with long term follow up of patients allow us to better assess the sensitivity and specificity of both methods. In the meantime, I am afraid we are not much further advanced in radiographic imaging of suspected pulmonary tuberculosis.

Arch Dis Child 2005;90:1104.

doi: 10.1136/adc.2005.072348

Correspondence to: Professor Ulrich Heininger, University Children's Hospital Basel, PO Box, 4005 Basel, Switzerland; Ulrich.Heininger@ unibas.ch

Competing interests: none declared

\section{REFERENCES}

1 World Health Organization. http:// www.who.int/tb/publications/global_report/en/. 2 Wallgren A. On contagiousness of childhood tuberculosis. Acta Paediatr 1937;22:229-34.

3 Swingler GH, du Toit G, Andronikou S et al. Diagnostic accuracy of chest radiography in detecting mediastinal lymphadenopathy in suspected pulmonary tuberculosis. Arch Dis Child 2005;90:1153-6.

4 Starke J, Smith KC. Tuberculosis. In: Feigin RD, Cherry JD, eds. Textbook of pediatric infectious diseases. 5th ed. Philadelphia: WB Saunders, 2004:1337-79.

5 Andronikou S, Brauer B, Galpin J, et al. Interobserver variability in the detection of mediastinal and hilar lymph nodes on CT in children with suspected pulmonary tuberculosis. Pediatr Radiol 2005;35(4):425-8.

6 Landis JR, Koch GG. The measurement of observer agreement for categorical data. Biometrics 1977;33:159-74. 
Abuse

\section{Is protecting children bad for your health?}

\section{M B Hall}

\section{Commentary on the paper by Bennett et al (see page 1112)}

I the last few years a series of child abuse tragedies and fiercely contested murder trials has put paediatricians under the spotlight as never before. There is a growing reluctance among consultants and trainees to get involved in child protection. The attempt by Bennett and colleagues ${ }^{1}$ to measure and analyse the stress and burnout among child protection professionals in Canada is, therefore, very timely-but inevitably it also poses a number of further questions. Can slippery concepts like stress and burnout be reliably defined in operational terms? Is child protection different from other healthcare tasks and if so, does it affect different disciplines in different ways? Are there differences between countries and if so, do these relate to their cultural attitudes or child protection systems? Do stress and burnout affect people in other walks of life? And, most important, what are the risk factors for burnout and what might be done to reduce the risks of these (presumably) negative consequences of such work?

\section{DEFINING THE TERMS ${ }^{2}$}

The literature uses various terms with related but sometimes poorly defined meanings: stress, burnout, compassion fatigue, secondary traumatic stress reactions (STS) or vicarious traumatisation (VT), and traumatic countertransference (a psycho-analytic term).

Stress can be defined as "demands (internal or external) that are judged by an individual to tax or exceed their resources" and coping is defined as "behaviours, thoughts, and feelings adopted to protect against stress". Burnout is a prolonged response to chronic emotional and interpersonal stressors on the job, and is defined by the three dimensions of mental and physical exhaustion, indifference and cynicism, and a sense of failure as a professional and as a person. The warning signs of impending burnout include anger, hostility, and reduced productivity or effectiveness at work. Depression may be a prominent feature and may overlap with burnout. Other responses include the avoidance of problems and decisions, ambiguity about managers' expectations, and reduced success in meeting them.

The term compassion fatigue was coined by Joinson in 1992, to describe nurses who were worn down by daily hospital emergencies. The dictionary meaning of compassion is a "feeling of deep sympathy and sorrow for another who is stricken by suffering or misfortune, accompanied by a strong desire to alleviate the pain or remove its cause". Compassion fatigue describes a reduced capacity or interest in being empathic or "bearing the suffering of others" and may be the price of caring without reward or result.

Posttraumatic stress is a natural consequence to a markedly distressing and unusual human event; secondary traumatic stress (vicarious traumatisation) is a natural consequence resulting from knowing about or witnessing a traumatising event experienced by a significant other.

Within the healthcare professions, the causes of stress and burnout vary according to the discipline involved. For example, in one study paediatric oncology nurses were found to have a preoccupation with death and dying, they saw themselves as fighters in the "war" against cancer, and they resented their perceived inferior professional status compared with that of physicians. Nurses who care for children with chronic disabling disorders may suffer more compassion fatigue than those who work in critical care where there is sometimes the reward of dramatic recovery against the odds. Intensivists and accident and emergency consultants have high levels of stress related to their perceived workload, lack of resources, and disrupted family life.

\section{WHAT IS DIFFERENT ABOUT CHILD PROTECTION?}

Healthcare professionals may suffer secondary traumatic stress in some cases of child abuse, but many factors probably make this work more stressful than dealing with illness or accidental trauma. There is often much doubt about whether or not abuse has occurred and these doubts, unlike many other clinical conundrums, often remain unresolved either by investigations or by the passage of time. Management of suspected child abuse is usually shared with or handed to other professionals such as social workers or the police and, for many health staff, this loss of control and a lack of mutual trust and respect between disciplines add to their anxiety. For community based staff, working in deprived areas away from the (relative) safety of the hospital, there is a growing concern about intimidation, violence, and personal safety whenever child care or protection issues are raised. But these issues are not new and do not account for the recent reluctance of many paediatric staff to deal with these problems.

It is widely believed - though hard to confirm - that the change in attitude to child protection is primarily the result of high profile complaints against professionals by aggrieved parents. ${ }^{3}$ Doctors are the usual subjects of such complaints, though nurses have also been involved. A minority of cases involve straightforward clinical errors in diagnosis, such as mistaking osteogenesis imperfecta for non-accidental injury, but most have been related to the contentious issues of multiple unexplained infant deaths in a family or to suspected fabricated or factitious illness. There have also been a number of fiercely contested cases of chronic fatigue syndrome, where professional perceptions clash with those of the parents to the extent that child protection proceedings are considered.

Complaints of this kind can be launched through several different routes and it may be years before the matter is resolved. Parents who wish to pursue a grievance can obtain information and network with others in similar circumstances around the world, using the internet. Websites are used to name and abuse those who are perceived to be responsible for initiating child protection proceedings. ${ }^{4}$ Verbal and even physical assaults on other members of doctors' families have been reported. Systematic and unrelenting attacks on some staff are undoubtedly designed to destroy their careers.

\section{IS THERE ANYTHING UNIQUE ABOUT STRESS AND BURNOUT IN THE HEALTHCARE PROFESSIONS?} Doctors are not alone in facing unprecedented and often orchestrated hate campaigns.

An internet search using the terms stress, burnout, or compassion fatigue combined with police officer, teacher, or priest produces a wealth of material on this theme, including some black humour. 
Mother to son: Time to get up and go to school.

Son: I don't want to go. It's too hard and the kids don't like me.

Mother: But you have to go-you're their teacher!

For teachers, complaints about verbal, physical, or sexual abuse are a constant threat and one that can be exploited by pupils. A public campaign against certain police officers continues 15 years after the Hillsborough football stadium disaster, in which they were blamed for inadequate crowd control. Fear of a child protection disaster hangs over social workers.

\section{HOW TO REDUCE STRESS AND BURNOUT IN CHILD PROTECTION WORK}

No health professional who sees children, or who has adult patients with children, can ignore possible child abuse. If the complaints culture is indeed the biggest cause of stress and burnout, it is important to minimise these by straightforward measuresgood initial training and continuing education, familiarity with national and local guidelines, willingness to consult and obtain second opinions when in doubt, access to designated experts, a debrief with colleagues after dealing with particularly stressful cases, good legal advice, and the support of senior management. Follow up of abused children will remind staff that a well conducted child protection case can be just as rewarding as solving a more typically "medical" problem.
Unfortunately, adherence to good practice is no longer enough. Some countries have adopted mandatory reporting-any professional who has any suspicion about child abuse has an obligation to report it to the relevant authorities. ${ }^{6}$ There is however no clear evidence that this effectively protects professionals against complaints. An alternative approach would be to introduce mandatory protection for professionals when reporting possible abuse, so that anyone acting in what they reasonably believe to be the child's best interests would be immune from complaints even if the concern turned out to be unfounded. Current legal opinion suggests that the Children Act 1989 already offers such protection if interpreted as Parliament intended, by the courts and the regulatory authorities. The principle that the child's interests are paramount was reaffirmed recently when the Law Lords ruled in three cases that the professional's duty of care was solely to the child and not to the parents. ${ }^{7}$

The regulatory authorities should now take account of this judgment and consider a change in the initial evaluation of complaints against staff in respect of child protection work. ${ }^{8}$ Concerns about a professional's behaviour or competence raised by a magistrate, judge, or director of social services must be investigated, but the regulatory authorities should not accept complaints about child protection work initiated by members of the public unless they have first been investigated and upheld by an appropriate local multi-agency procedure.
Child protection work must be done to the highest standards and there can be no excuse for careless diagnosis or incorrect procedures, but changes in child protection systems are now urgently needed to address the problems highlighted by the Canadian team.

Arch Dis Child 2005;90:1 105-1106.

doi: 10.1136/adc.2005.072256

Correspondence to: Prof. D M B Hall, Storrs House Farm, Storrs Lane, Sheffield S6 6GY, UK; d.hall@sheffield.ac.uk

Competing interests: none declared

\section{REFERENCES}

1 Bennett S, Plint A, Clifford TJ. Burnout, psychological morbidity, job satisfaction, and stress: a survey of Canadian hospital based child protection professionals. Arch Dis Child 2005;90:1112-6.

2 Huggard P. Compassion fatigue: how much can I give? Med Educ 2003;37:163-4.

3 Kmietowicz Z. Complaints against doctors in child protection work have increased five-fold. BMJ 2004;328:601.

4 MAMA (Mothers against Munchausen syndrome by proxy allegations). www.msbp.com (accessed 8 April 2005).

5 Center for Mental Health in Schools at UCLA. An introductory packet on understanding and minimizing staff burnout. Los Angeles, CA, 2004 http://smhp.psych.ucla.edu (accessed 5 April 2005).

6 Bell L, Tooman P. Mandatory reporting laws: a critical overview. International Journal of Law and the Family 1994;8:337-56.

7 Judgments-JD (FC) (Appellant) v. East Berkshire Community Health NHS Trust and others (Respondents) and two other actions (FC). 21 April 2005. UKHL 23. http:// www. publications. parliament.uk/pa/ld200405/ Idjudgmt/jd050421/east-1.htm (accessed 12 June 2005).

8 Marcovitch H. GMC must recognise and deal with vexatious complaints fast. $B M$ 2002;324: 167

\section{IMAGES IN PAEDIATRICS}

\section{Kayser Fischer ring}

A 12 year old girl was admitted for poor school performance, and slurring of speech for the past three months. Of late she was noticed to have involuntary movements and tremors. She also had mood changes. She had no significant past illness. Family history was insignificant except that her brother had recurrent episodes of jaundice from the age of 5 years. Examination revealed mild hypertonicity of all four limbs, ataxia, and intention tremor with mild pallor. Examination of the eyes suggested the diagnostic approach.

Kayser Fischer ring is a golden brown deposit at the level of the Descemet's membrane of the cornea, and is seen in various conditions such Wilson's disease and primary biliary cirrhosis.

Kayser Fischer ring is seen in most Wilson disease cases presenting with neurological symptoms. It may be visualised sometimes with the naked eye examination, but a slit lamp examination is always required to rule it out.

B Kerur, S Kumar Royal Albert Edward Infirmary, Wigan, UK

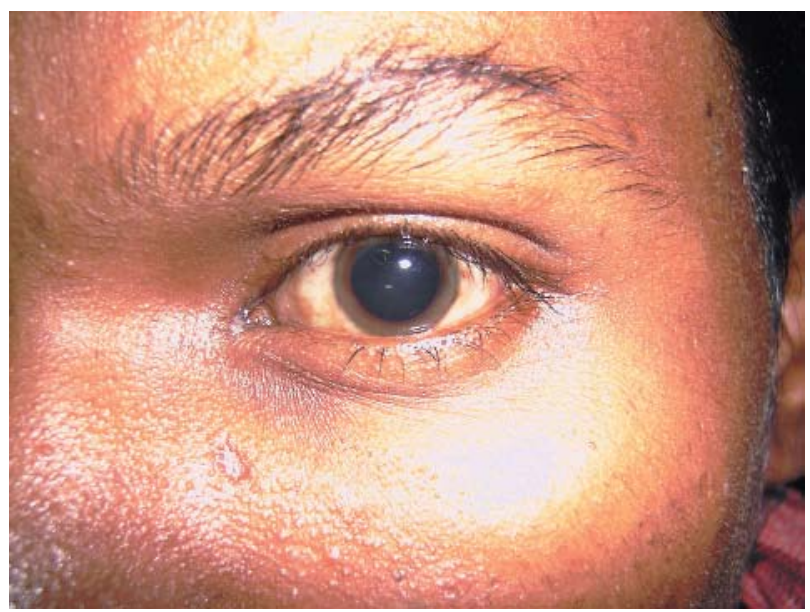

doi: 10.1136/adc.2005.076364

Correspondence to: Dr B Kerur, Department of Paediatrics, Royal Albert Edward Infirmary, Wigan WN1 2LA, UK; basavarajdoc@yahoo.com Competing interests: none declared Consent was obtained for publication of this figure 